\title{
Suppression of Phytophthora cinnamomi in Potting Mixes Amended with Uncomposted and Composted Animal Manures
}

\author{
I. P. Aryantha, R. Cross, and D. I. Guest
}

First and third authors: School of Botany, The University of Melbourne, Parkville, Victoria 3053, Australia; second author: Royal Botanic Gardens Melbourne, Birdwood Avenue, South Yarra, Victoria 3141, Australia.

Current address of I. P. Aryantha: Department of Biology, Institute of Technology Bandung, Ganesha 10, Bandung 40132, Indonesia.

Accepted for publication 12 March 2000

\begin{abstract}
Aryantha, I. P., Cross, R., and Guest, D. I. 2000. Suppression of Phytophthora cinnamomi in potting mixes amended with uncomposted and composted animal manures. Phytopathology 90:775-782.

We examined the effects of fresh and composted animal manures on the development of root rot, dieback, and plant death caused by Phytophthora cinnamomi. Fresh chicken manure, or chicken manure composted for 5 weeks before incorporation into the potting mix $(25 \%$, $\mathrm{vol} / \mathrm{vol}$ ), significantly reduced pathogen survival and the development of symptoms on Lupinus albus seedlings. Chicken manure composted for 2 weeks was less suppressive. Cow, sheep, and horse manure, whether fresh or composted, did not consistently suppress populations of $P$. cinnamomi or disease symptoms at the rates used $(25 \%$, vol/vol). All composts increased organic matter content, total biological activity, and populations of actinomycetes, fluorescent pseudomonads, and fungi. Only chicken manure stimulated endospore-forming bacteria, a factor

that was strongly associated with seedling survival. Fallowing the potting mix for an additional 8 weeks after the first harvest increased the survival of lupin seedlings in a second bioassay, with survival rates in chicken manure compost-amended potting mix exceeding $90 \%$. These data suggest that the ability of composted manure to stimulate sustained biological activity, in particular the activity of endospore-forming bacteria, is the key factor in reducing disease symptoms caused by $P$. cinnamomi. Supporting these results, the survival of rooted cuttings of Thryptomene calycina was significantly higher in sand-peat potting mix following amendment with commercially available chicken manure $(15 \%$ $\mathrm{vol} / \mathrm{vol})$. However, this protection was reduced if the potting mix was steam pasteurized before amendment, indicating that suppression was due to endogenous as well as introduced microbes. Chicken manure compost incorporated at $5 \%(\mathrm{vol} / \mathrm{vol})$ or more was strongly phytotoxic to young Banksia spinulosa plants and is not suitable as an amendment for phosphorus-sensitive plants.
\end{abstract}

Organic mulching is an ancient gardening and farming practice developed to nurture favorable physical, chemical, and biological environments in the soil. Mulching with organic material stimulates plant root growth, increases nutrient uptake, decreases evaporation from the soil, increases soil water-holding capacity, reduces surface water runoff, facilitates drainage, regulates soil temperature, and provides a rich substrate for soil microbes $(4,5,15)$. Soils with high levels of organic matter have a more complex and active microflora and fauna associated with their ability to suppress the activity of the root rot pathogen, Phytophthora cinnamomi Rands $(2,7)$.

Composts and manures harbor their own populations of microorganisms, and microbial populations change during composting (7). Depending on their state of decomposition and quality, composts may result in the amended soil becoming either conducive or suppressive to disease $(7,8)$. Roy and Newhook (16) found that more sporangia were produced by $P$. cinnamomi when soils were treated with fresh cow dung and urine and postulated that this contributed to increased tree deaths around farm shelter belts. Hoitink et al. (8) proposed composting to high temperatures to ensure that pathogens are killed, followed by the amendment of mature composts with exotic biocontrol agents as a way of improving the reliability of composts.

In addition to sometimes increasing the severity of plant diseases, manures may also cause phytotoxicity. Many plants belonging to the family Proteaceae, for example, evolved on

Corresponding author: D. I. Guest

E-mail address: d.guest@ botany.unimelb.edu.au

Publication no. P-2000-0502-01R

(C) 2000 The American Phytopathological Society phosphorus-deficient soils and have a low tolerance for increases in soil phosphorus levels resulting from compost amendments (11).

The objectives of this study were: (i) to evaluate the potential of composted manures to reduce the incidence of symptoms caused by $P$. cinnamomi) using Lupinus albus $\mathrm{L}$. seedlings as a model; (ii) to investigate whether the length of composting affects the ability of manures to reduce their activity against $P$. cinnamomi; (iii) to investigate which changes in soil characteristics (including $\mathrm{pH}$, nutrient levels, total and specific biological activities) following compost application are critical to the control of P. cinnamomi; and (iv) to assess effects of chicken manure composts on disease caused by P. cinnamomi on the two horticulturally important plant species Thryptomene calycina (Lindl.) Stapf and Banksia spinulosa Sm. L. albus was chosen as a model in the initial screens of manures because it is readily available and inexpensive, grows rapidly from seed, and rapidly develops easily diagnosed root rot symptoms when inoculated with $P$. cinnamomi.

\section{MATERIAL AND METHODS}

Assessment of composts using $\boldsymbol{L}$. albus. Potting mix type A (3:3:2, vol/vol/vol, Mt. Derimut red-brown soil [a haplic hypocalcic chromosol]/vermiculite/washed river sand adjusted to $\mathrm{pH} 7.0$ with dolomite lime) was used in this experiment. The soil and sand components were passed through a 3-mm sieve and mixed thoroughly with the appropriate amount of vermiculite. Water was added to field capacity. Chicken, cow, horse, and sheep manures were collected fresh, ground, mixed $(25 \%$, vol/ $/ \mathrm{vol})$ in potting mix type A, and composted in 15-liter batches, with weekly turning in closed 25 -liter plastic drums for 0,2 or 5 weeks. Potting mixes without manure, but with identical composting treatments, were used as controls. P. cinnamomi bran-sand ino- 
culum (22) was added at a rate of $10 \%$ ( $\mathrm{vol} / \mathrm{vol})$ to $10-\mathrm{cm}-$ diameter pots, each containing $1,000 \mathrm{ml}$ of composted potting mix. The same volume of sterile bran-sand was added to uninoculated control pots.

Population sizes of $P$. cinnamomi were estimated from serial dilutions of 1.0-g soil samples into $9.0 \mathrm{ml}$ of sterile distilled water. One milliliter of each dilution was plated onto $\mathrm{PCH}$ medium (pentachloronitrobenzene [Terrachlor $750 \mathrm{~g} \mathrm{~kg}^{-1}$ a.i., Uniroyal Chemical Co., Regency Park, SA, Australia]/chloramphenicol [Sigma Chemical Co., St. Louis]/hymexazol [Sankyo, Tokyo, Japan]), a selective medium for $P$. cinnamomi (19). Plates were incubated at $20^{\circ} \mathrm{C}$ for $48 \mathrm{~h}$ before colonies were counted with the aid of a dissecting microscope. Using this technique, mean population densities of $P$. cinnamomi were estimated immediately after the inoculum was mixed with the composted potting mix (i.e., week 0 in Fig. 1) as $1.02 \times 10^{2} \mathrm{CFU} / \mathrm{g}$ of soil.

Composts were then screened for their abilities to reduce the incidence of $P$. cinnamomi symptoms on L. albus seedlings. Seeds were germinated in moist paper towels for 2 days at $25^{\circ} \mathrm{C}$, planted immediately after the incorporation of $P$. cinnamomi inoculum into the appropriate potting mix, and allowed to grow in a glasshouse at 15 to $21^{\circ} \mathrm{C}$ and $50 \%$ relative humidity. Pots were watered from the tap every second day and allowed to drain freely. The number of surviving seedlings in each pot was assessed after 2 weeks. The seedlings were harvested, and the pots left undisturbed and fallow, with watering on alternate days, for an additional eight weeks. The pots were then resown with an additional ten pregerminated lupin seedlings inserted into freshly drilled holes, watered daily for 2 weeks, and assessed for survival. The experimental protocol is summarized in Figure 1. Each amendment treatment was replicated three times.

Throughout the entire experiment, soil samples were collected every 14 days for analysis of chemical and biological characteristics. Organic matter was determined by the Walkley-Black method on $0.5 \mathrm{~g}$ soil samples (14). Soil $\mathrm{pH}$ was determined by suspending $5.0 \mathrm{~g}$ of soil in $10 \mathrm{ml}$ deionized water, then measuring the $\mathrm{pH}$ of the supernatant after $1 \mathrm{~h}$. Total microbial activity was estimated by determining the rate of hydrolysis of fluorescein diacetate (18), a good indicator of disease suppressiveness (7). Briefly, 5.0-g soil samples were mixed with $20 \mathrm{ml}$ phosphate buffer (60 mM, pH 7.6), to which $400 \mu \mathrm{g}$ of fluorescein diacetate (FDA.; Sigma) was added. The mixture was shaken for $20 \mathrm{~min}$ at $90 \mathrm{rpm}$ and $24^{\circ} \mathrm{C}$ before the addition of $20 \mathrm{ml}$ of acetone to stop the hydrolysis. The supernatant was filtered through Whatman No. 1 filter paper (Whatman International, Maidstone, England), and the absorbance assayed at $490 \mathrm{~nm}$. Microbial activity is presented as micrograms of FDA hydrolyzed per gram of soil per minute. Controls were prepared by adding acetone to the buffered soil suspension at the same time as the FDA, and a standard curve was prepared by boiling a range of FDA concentrations from 0 to $1,000 \mu \mathrm{g} \mathrm{ml} \mathrm{m}^{-1}$ in $5 \mathrm{ml}$ of buffer to complete hydrolysis and measuring the absorbance of the resulting supernatant at $490 \mathrm{~nm}$. Microbial populations were counted using dilution plating onto appropriate selective media ( $\mathrm{PCH}$ as described earlier) to enumerate populations of $P$. cinnamomi, actinomycetes $(2 \%$ colloidal chitin agar; 12), fungi (potato dextrose agar supplemented with $1 \% \mathrm{vol} / \mathrm{vol}$ chloramphenicol) and fluorescent pseudomonads (NPC medium containing novobiocin at $45 \mathrm{mg}$ liter $^{-1}$ [Sigma], penicillin $\mathrm{G}$ at $46 \mathrm{mg} \mathrm{liter}^{-1}$ [Sigma], and cycloheximide at $75 \mathrm{mg} \mathrm{liter}^{-1}$ [Aldrich Chemical Co. Inc., Milwaukee, WI; 17]). Endospore-forming bacteria were counted by heating the diluted soil suspensions to $80^{\circ} \mathrm{C}$ for $10 \mathrm{~min}$ before plating nutrient agar supplemented after autoclaving with Nilstat at $1 \mathrm{mg} \mathrm{liter}{ }^{-1}(100,000$ units of Nystatin per ml; Lederle Laboratories, Baulkham Hills, NSW, Australia; 25).

Effects of chicken manure compost on root rot of $T$. calycina and $\boldsymbol{B}$. spinulosa. The effectiveness of chicken manure compost in the lupin trial encouraged us to investigate its effectiveness
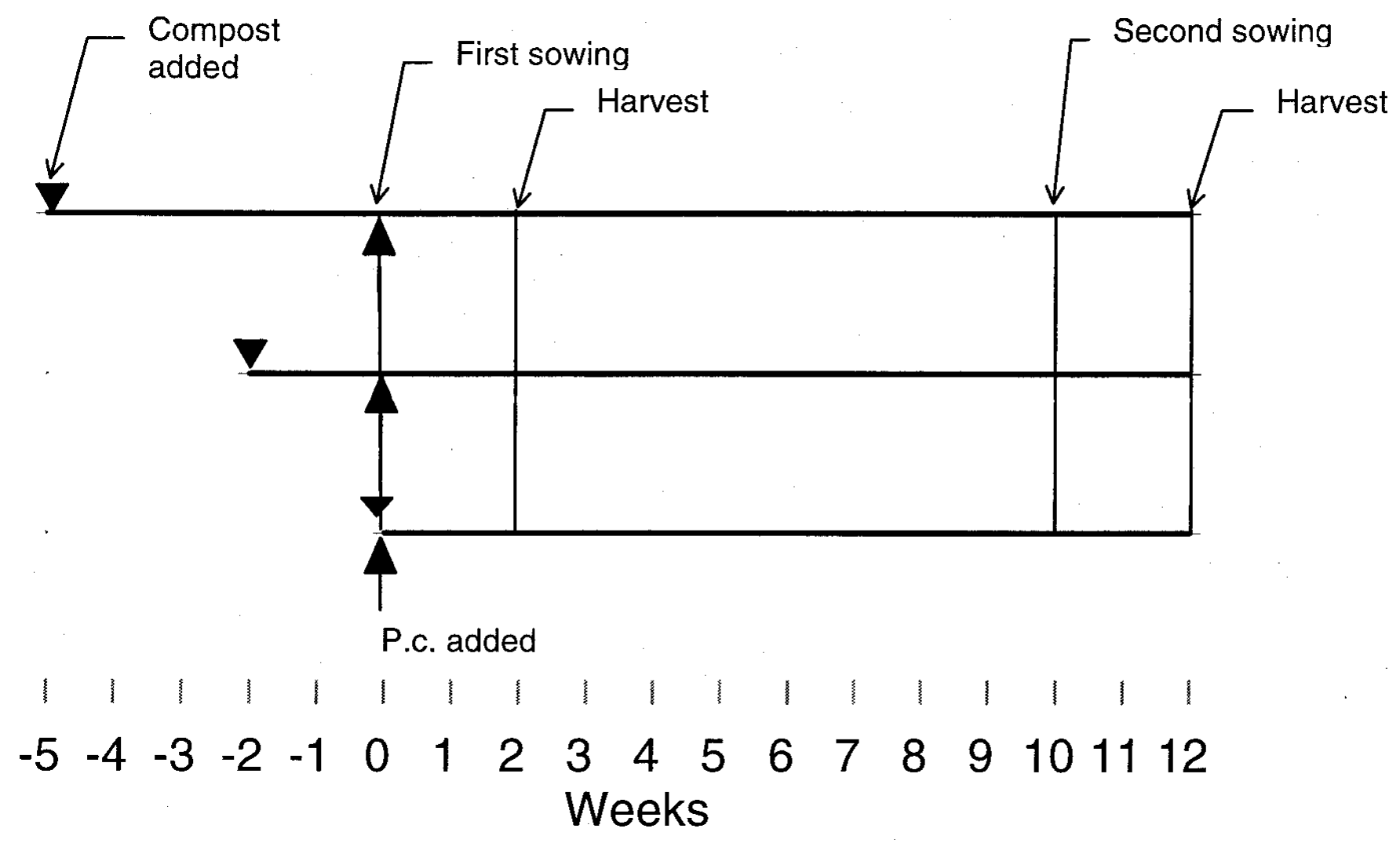

Fig. 1. Design of the Lupinus albus bioassay to compare the effects of composted manures on the incidence of root rot caused by Phytophthora cinnamomi (P.C.). 
against $P$. cinnamomi on the important cut-flower species $T$. calycina (Myrtaceae) and B. spinulosa (Proteaceae). In these experiments we used commercially available steam-pasteurized and powdered chicken manure compost (Munro Street Nursery, Victoria, Australia) rather than fresh chicken manure. We also used a lower rate (15\%) of compost in the potting mix, as preliminary experiments revealed that $25 \%$ compost causes leaf yellowing and leaf burn in T. calycina and B. spinulosa. To determine whether disease suppression resulted from amendmentinduced changes to the chemistry or biology of the potting mix, we compared the activities of chicken manure when added to steam-pasteurized or unpasteurized potting mix. Chicken manure was added $(15 \% \mathrm{vol} / \mathrm{vol})$ to steam-pasteurized potting mix B (peat moss-sand, $1: 1, \mathrm{vol} / \mathrm{vol}, \mathrm{pH}=7.0)$. The bran-sand-P. cinnamomi inoculum was then incorporated into the potting $\operatorname{mix}(10 \%$, vol/vol), which was then planted with 3-month-old T. calycina cuttings or $B$. spinulosa seedlings. Plant survival was assessed monthly for 6 months ( $T$. calycina) or 4 months (B. spinulosa). Populations of $P$. cinnamomi were assessed by soil dilution on PCH medium, as described above, 4 and 5 months after transplanting (in the $T$. calycina trial) or 1 and 2 months after transplanting (in the B. spinulosa trial). Each treatment was replicated in 10 pots, including controls without chicken manure compost or the pathogen.

Phytotoxicity trial on $\boldsymbol{B}$. spinulosa. Chicken manure compost incorporated to $15 \%(\mathrm{vol} / \mathrm{vol})$ of the potting mix in the above trial caused a severe phytotoxic reaction in B. spinulosa. An experiment was designed to investigate the phytotoxicity of reduced proportions of chicken manure compost $(2.5,5,10$ and $15 \%$, vol/vol) in pathogen-free, sterile river sand. The available inorganic phosphorus concentration of each treatment was analyzed at the time of planting $(1,21)$. Ten replicate pots, each containing $500 \mathrm{ml}$ of potting mix, were each planted with a 3month-old B. spinulosa seedling. Plant survival was assessed weekly for 6 weeks and compared with survival in unamended river sand.

Data analysis. Data collected from all trials were analyzed statistically using MINITAB, version 11 (Minitab, Inc., University Park, PA). Continuous data (microbial activity, organic matter, $\mathrm{pH}$, microbial populations) were compared using ANOVA, while categorical data, such as plant survival, were analyzed using logistic regression analysis. Significant differences and odds ratios (6) were inferred at the $95 \%$ confidence level.

TABLE 1. Logistic regression analysis of the correlation between the survival of Lupinus albus seedlings grown in Phytophthora cinnamomiinfested potting mixes amended with manures in relation to survival on unamended, infested potting mix $^{\mathrm{a}}$

\begin{tabular}{lrrrrc}
\hline Treatment & Coefficient $^{\mathrm{b}}$ & $\mathrm{SD}^{\mathrm{c}}$ & \multicolumn{1}{c}{$Z^{\mathrm{d}}$} & $P^{\mathrm{e}}$ & Odds ratio $^{\mathrm{f}}$ \\
\hline Chicken & 1.0225 & 0.2831 & 3.61 & 0.000 & 2.78 \\
Cow & -0.0335 & 0.2589 & -0.13 & 0.897 & 0.97 \\
Horse & -0.3341 & 0.2591 & -1.29 & 0.197 & 0.72 \\
Sheep & 0.0673 & 0.2595 & 0.26 & 0.795 & 1.07 \\
\hline
\end{tabular}

${ }^{a}$ Data pooled from survival counts at harvests 2 and 12 weeks after amendment of $P$. cinnamomi-infested soils with fresh or composted manures (data presented in Figure 2). Each treatment was replicated at each harvest with 10 seedlings per pot and 6 pots per treatment $(n=120$ seedlings per treatment).

${ }^{\mathrm{b}}$ Coefficient of variation.

c Standard deviation of the mean

${ }^{\mathrm{d}}$ The $Z$ statistic is the coefficient of variation/standard deviation ratio. A $Z$ score greater than 2 indicates that the coefficient of variation is significantly different than $0(P<0.05)$.

e Significance of the $Z$ score.

${ }^{\mathrm{f}}$ The odds ratio estimates the increased (or decreased) likelihood that a seedling will survive if grown on potting mix amended with a particular composted manure compared with its chances of survival on unamended potting mix.

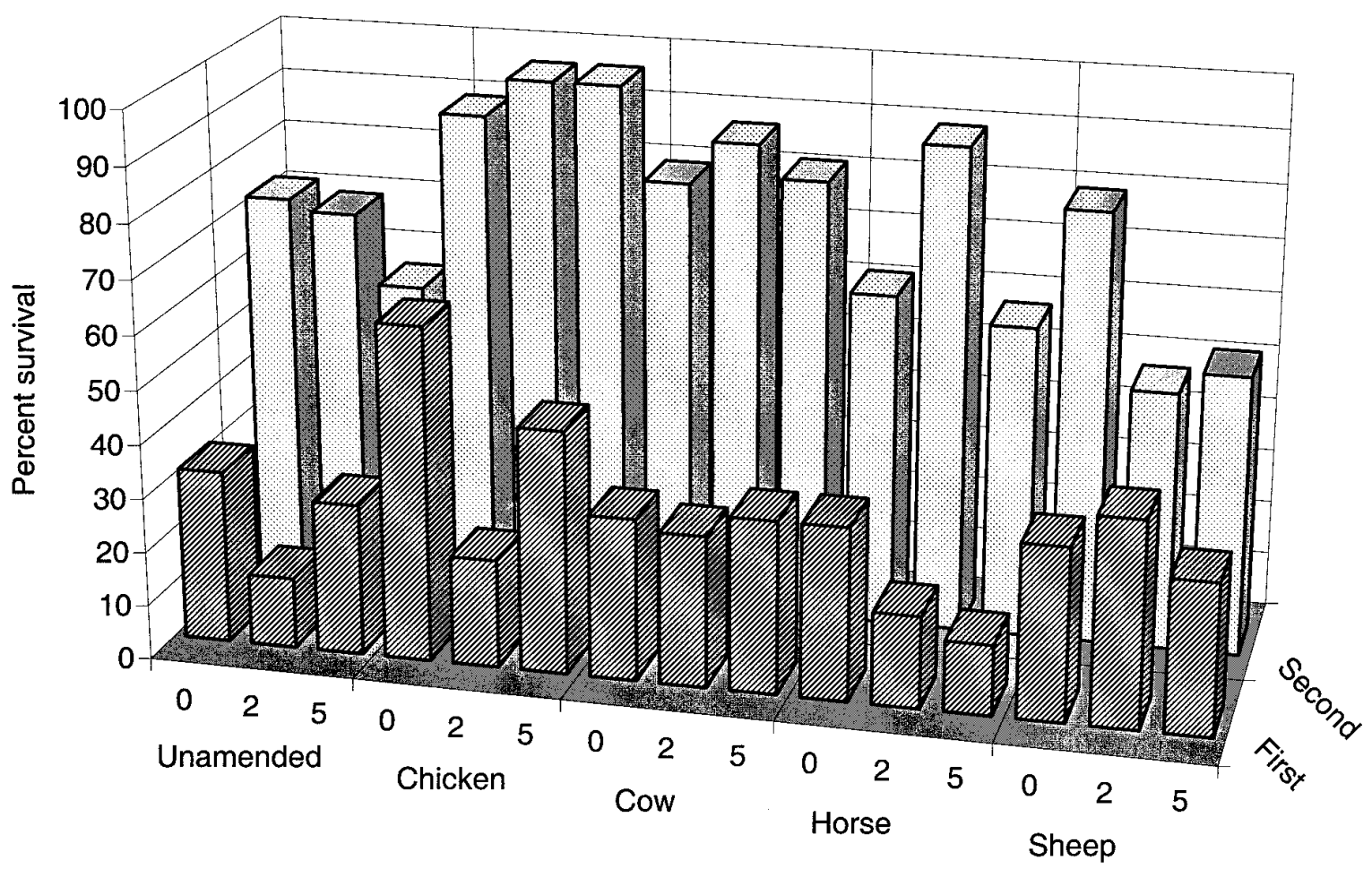

Fig. 2. Effect of animal manures on the survival of Lupinus albus seedlings grown in Phytophthora cinnamomi-infested, soil-based potting mix. Germinated $L$. albus seedlings (first planting) were transplanted into potting mix containing 15\% (vol/vol of chicken, cow, horse, or sheep manure that had been composted for 0,2 , or 5 weeks. Sand-bran P. cinnamomi inoculum was incorporated into potting mixes immediately before planting. Unamended potting mix included $P$. cinnamomi but no manures. Seedling survival was rated, and surviving seedlings harvested after 2 weeks (first planting). Pots were then left fallow for 8 additional weeks before replanting with freshly germinated lupin seedlings (second planting) that were rated for survival 2 weeks later. Seedling survival was $100 \%$ in uninoculated potting mix in all amendments. Data analysis are shown in Table 1. 


\section{RESULTS}

Survival of L. albus on amended soils. In all treatments, seedling survival was lower in pots freshly inoculated with $P$. cinnamomi (first harvest 2 weeks after inoculation) than in pots that had been fallowed for an additional 8 weeks (second harvest
12 weeks after inoculation) (Fig. 2). Logistic regression analysis of survival data 2 and 12 weeks after the incorporation of uncomposted or composted manures indicates that only amendment with chicken manure (regardless of composting) significantly increased seedling survival (Table 1). Fresh or 2- or 5week composted chicken manures also significantly increased
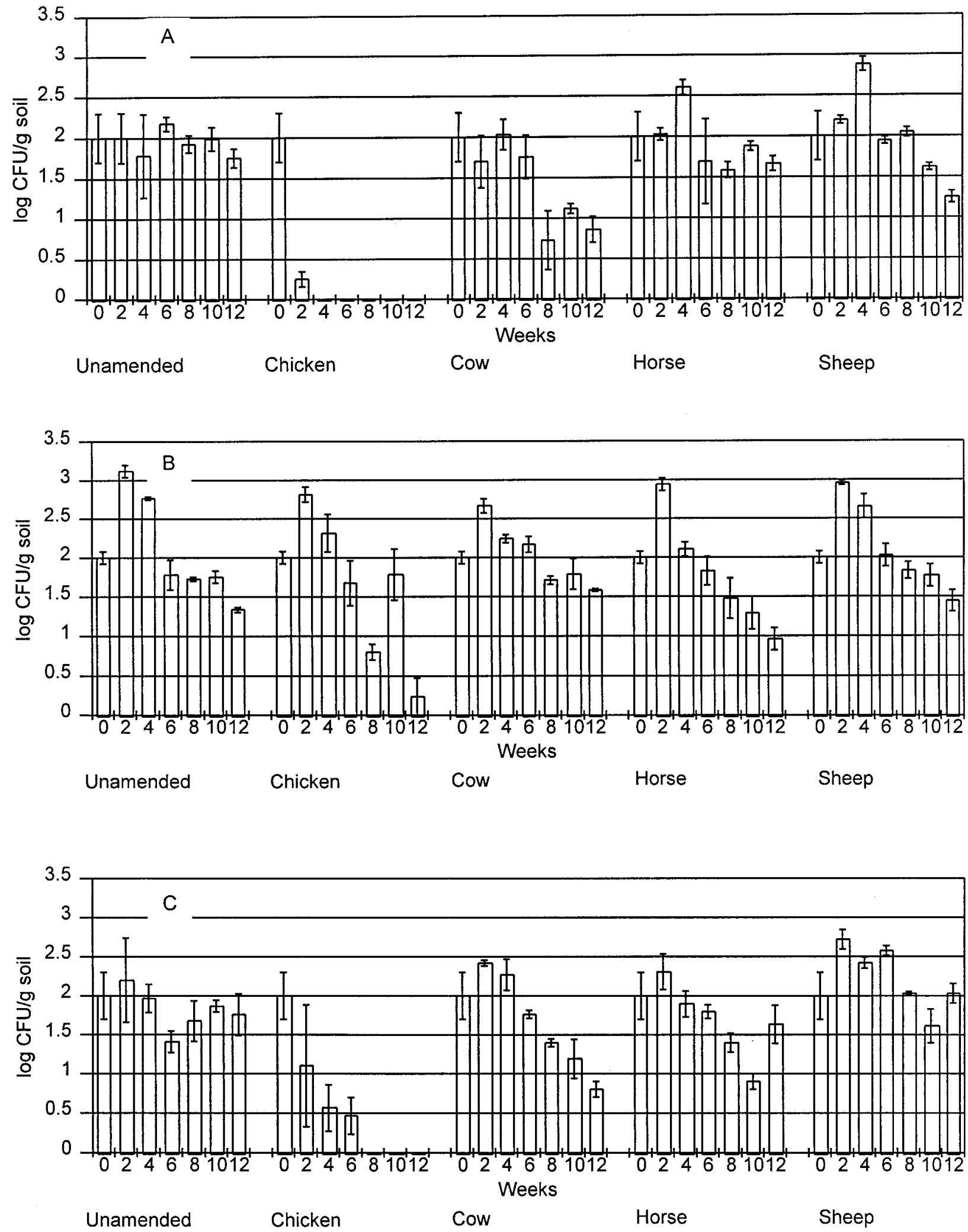

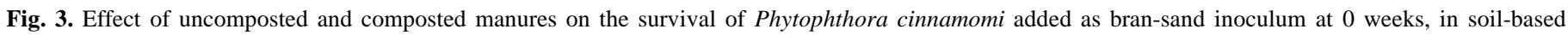

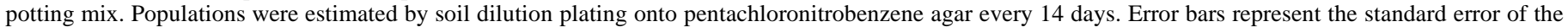
mean. A, Fresh manure amendments; B, manure amendments composted for 2 weeks; C, manure amendments composted for 5 weeks. 
seedling survival when analyzed independently. Of the other manures, only cow manure composted for 5 weeks increased seedling survival when analyzed independently (odds ratio $=1.49, P=$ 0.007). Put another way, lupin seedlings grown in pathogeninfested potting mix are 2.78 times more likely to survive if the potting mix was amended with chicken manure, or 1.5 times more likely to survive if it is amended with cow manure composted for 5 weeks.

Chicken manure amendments, whether composted or not, also reduced populations of $P$. cinnamomi after 12 weeks (Fig. 3;
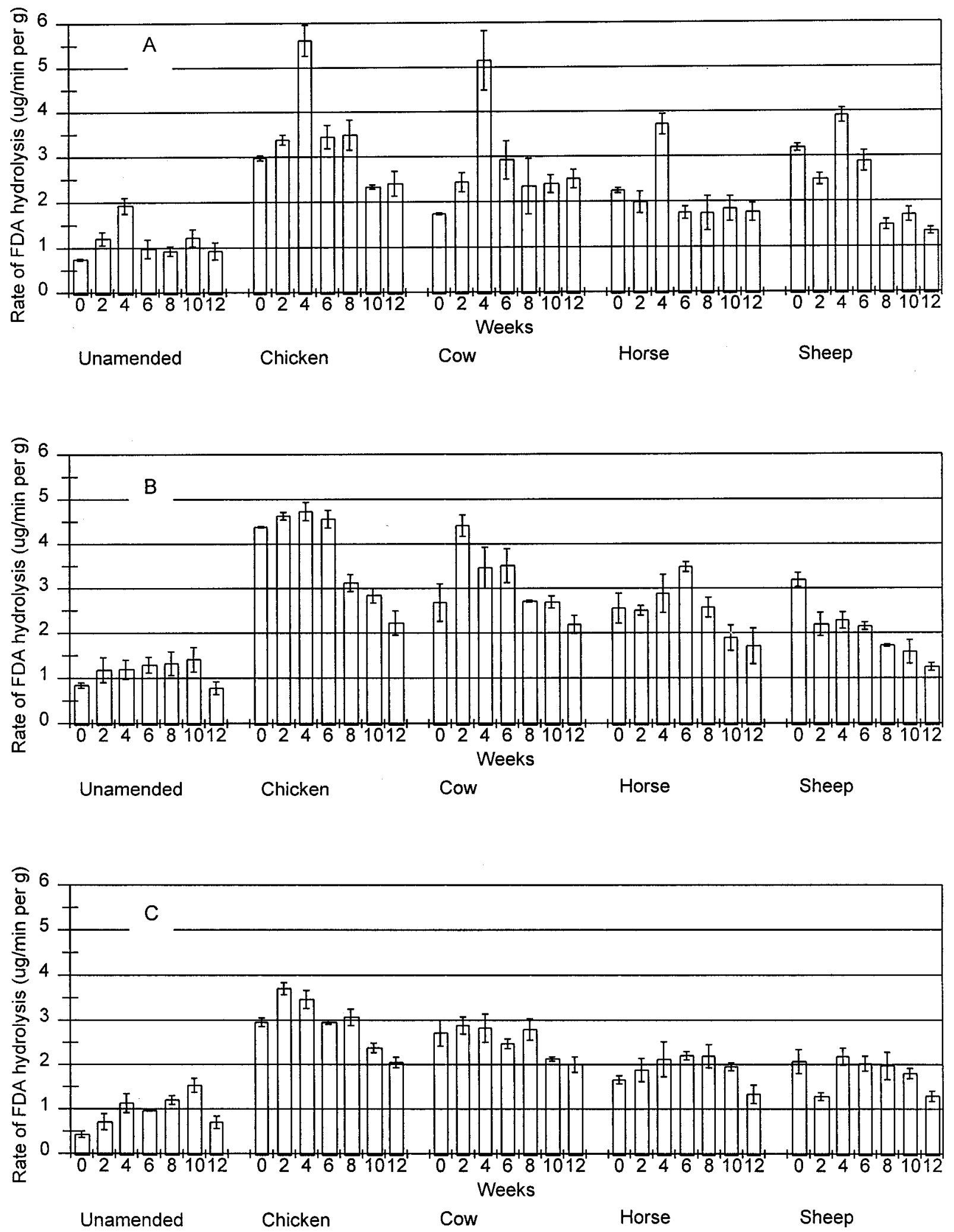

Fig. 4. Effect of animal manures and composting on the total biological activity, as measured by the rate of fluorescein diacetate hydrolysis (micrograms fluorescein diacetate hydrolyzed per minute per gram of dry soil) of soil-based potting mix inoculated with Phytophthora cinnamomi at week 0. Error bars represent the standard error of the mean. A, Fresh manure amendments; B, manure amendments composted for 2 weeks; C, manure amendments composted for 5 weeks. 
$P=0.000$ by ANOVA of data pooled from manure composted for $0,2$, and 5 weeks $)$. Fresh cow manure $(P=0.007)$ or cow manure composted for five weeks $(P=0.010)$ also reduced pathogen populations, while cow manure composted for 2 weeks did not. Horse and sheep manure amendments had no effect on pathogen populations or seedling survival.

The level of organic matter was increased significantly by all manure amendments. In unamended potting mix, the organic matter content varied between 4 and $6 \%$ over the 12 weeks of monitoring, while amended potting mixes contained 12 to $14 \%$ organic matter at first, gradually declining to 8 to $10 \%$ after 12 weeks (data not shown). Each of the manure amendments initially increased the soil $\mathrm{pH}$ from 7.0 to 7.5 to $\approx 8.0$; however, $\mathrm{pH}$ values returned to between 7.0 and 7.5 after 8 weeks (data not shown). Manure amendment also nonspecifically increased total biological activity as assayed by the rate of FDA hydrolysis (Fig. 4). Fresh chicken and cow manures caused the largest increase, stimulating total activity three- to fourfold for the first 4 to 6 weeks, before stabilizing at approximately double the rate in unamended potting mix.

The rate of FDA hydrolysis was determined by the population and relative activity of each of the biological components of the compost-amended potting mixes. Populations of endosporeforming bacteria in chicken manure-amended potting mix $(197 \times$ $\left.10^{6} \mathrm{CFU} / \mathrm{g}\right)$ were significantly higher $(P=0.000)$ than those in any other treatment or in unamended potting mix $\left(50 \times 10^{6}\right.$ $\mathrm{CFU} / \mathrm{g}$ ). Each manure initially stimulated the populations of actinomycetes, fungi, and fluorescent pseudomonads; however these increases were transient and were no longer significant 4 weeks after manure incorporation (data not shown). In each case, the initial flush of activity was more apparent with fresh rather than composted manures.

A strong positive association between the survival of lupin seedlings and total microbial activity (odds ratio $=3.83$, $P=0.000$ ) and populations of endospore-forming bacteria (odds ratio $=4.61, P=0.000$ ) was found with logistic regression analysis of the data pooled from all amendments (Table 2). The analysis also indicated a significant negative correlation between survival and organic matter content (odds ratio $=0.74, P=0.000$ ) or actinomycete populations (odds ratio $=0.32, P=0.000$ );

TABLE 2. Logistic regression analysis of the correlation between the survival of Lupinus albus seedlings in composted manure-amended potting mix infested with Phytophthora cinnamomi with total microbial activity, organic matter, populations of actinomycetes, endospore-forming bacteria, fungi, and fluorescent pseudomonads ${ }^{\mathrm{a}}$

\begin{tabular}{lccccc}
\hline Component & Coefficient $^{\mathrm{b}}$ & $\mathrm{SD}^{\mathrm{c}}$ & $Z^{\mathrm{d}}$ & $P^{\mathrm{e}}$ & Odds ratio $^{\mathrm{f}}$ \\
\hline $\begin{array}{l}\text { Microbial activity } \\
\text { Organic matter }\end{array}$ & 1.3429 & 0.1792 & 7.49 & 0.000 & 3.83 \\
$\quad$ & & & & & \\
$\quad$ content & -0.2974 & 0.0643 & -4.62 & 0.000 & 0.74 \\
pH Actinomycetes & -0.3317 & 0.2978 & -1.11 & 0.265 & 0.72 \\
$\begin{array}{l}\text { Endospore-forming } \\
\quad \text { bacteria }\end{array}$ & -1.1287 & 0.2412 & -4.68 & 0.000 & 0.32 \\
$\begin{array}{l}\text { Fluorescent } \\
\quad \text { pseudomonads }\end{array}$ & 0.9718 & 0.9121 & 1.01 & 0.314 & 2.50 \\
Total fungi & 1.0604 & 0.8292 & 1.28 & 0.201 & 2.89 \\
\hline
\end{tabular}

a Data pooled from soil samples taken every 2 weeks on potting mix amended with fresh or composted manures and analyzed in relation to unamended potting mix.

${ }^{\mathrm{b}}$ Coefficient of variation.

${ }^{c}$ Standard deviation of the mean.

d The $Z$ statistic is the coefficient of variation/standard deviation ratio. A $Z$ score of greater than 2 indicates that the coefficient of variation is significantly different than $0(P<0.05)$.

e Significance of the $Z$ score.

${ }^{\mathrm{f}}$ The odds ratio estimates the increased (or decreased) likelihood that a seedling will survive if grown on potting mix amended with a particular composted manure compared with its chances of survival on unamended potting mix. however, ANOVA indicated only that composted manures increased both parameters compared with unamended soils, with no significant differences between manure amendments.

T. calycina pot trial. Commercial chicken manure compost increased the survival rate of T. calycina to $50 \%$ after 6 months when added to the $P$. cinnamomi-infested, unpasteurized sand-peat mixture (odds ratio $=6.00, P=0.002$ ), whereas only $10 \%$ of plants survived in other treatments (Fig. 5). Death occurred most quickly for plants grown in unamended sand-peat and was delayed in plants grown in pasteurized sand-peat, whether chicken manureamended or not. P. cinnamomi populations fell below detectable levels in unpasteurized, chicken manure-amended treatments after 4 months, or after 5 months in chicken manure-amended pasteurized potting mix. In the absence of amendment, pasteurization did not affect the survival of $P$. cinnamomi $(60 \mathrm{CFU} / \mathrm{g}$ in pasteurized medium compared with $49 \mathrm{CFU} / \mathrm{g}$ in unpasteurized medium after 5 months).

During the first month, T. calycina showed mild phytotoxicity symptoms when grown in the presence of chicken manure compost at concentrations of $15 \%$ ( $\mathrm{vol} / \mathrm{vol})$. New leaf growth was yellow, although plants usually recovered in subsequent months.

B. spinulosa pot trial. Commercial chicken manure compost again significantly reduced the survival of $P$. cinnamomi in sandpeat potting mix (data not presented). While chicken manure amendments to unpasteurized sand-peat eradicated the pathogen within two months, $P$. cinnamomi survived at low levels in amended, pasteurized, potting mix. In unamended sand-peat the pathogen survived longer in steam pasteurized than in unpasteurized sand-peat.

Chicken manure amendments $(15 \%, \mathrm{vol} / \mathrm{vol})$ were phytotoxic to B. spinulosa, and the rates of plant death were similar to those in pots infested with $P$. cinnamomi, whether chicken manure amendments were used or not (Fig. 6). However, it was easy to distinguish root rot from phytotoxicity, as plants infected with $P$.
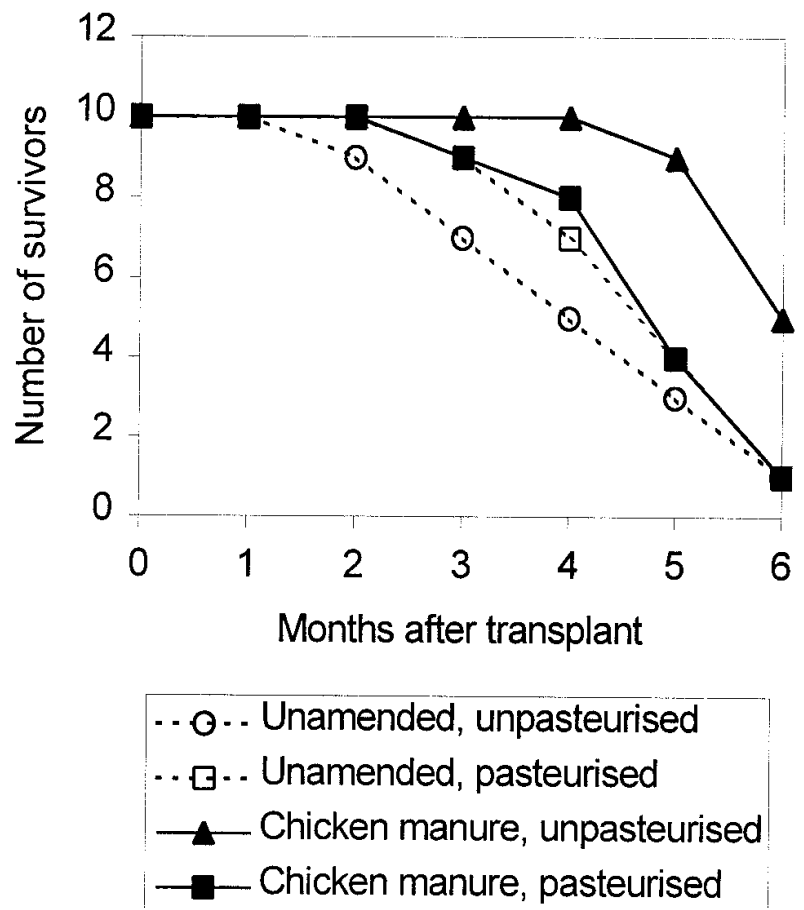

Fig. 5. Survival of Thryptomene calycina after transplanting into pasteurized or unpasteurized sand-peat potting mix amended with chicken manure, then inoculated with Phytophthora cinnamomi. The number of survivors indicates how many of the original 10 seedlings in each treatment were alive at each observation. Significantly more $(P \leq 0.05)$ seedlings survived on chicken manure compost-amended unpasteurized potting mix than on other substrates 4,5 , and 6 months after transplanting. 
cinnamomi became chlorotic, wilted rapidly and died. $P$. cinnamomi was invariably isolated from symptomatic roots on PCA. Plants grown on potting mix amended with chicken manure developed marginal leaf necrosis that eventually affected the entire lamina. In these plants, the entire canopy turned rusty brown and died without wilting.

Phytotoxicity trial on Banksia spinulosa. The presence of chicken manure compost at levels as low as $5 \%$ ( $\mathrm{vol} / \mathrm{vol})$ in washed river sand caused phytotoxicity in B. spinulosa (Fig. 7). The rate of plant death was related to phosphorus concentrations, which increased with the amount of chicken manure added. Unamended potting mix contained $8 \mu \mathrm{g}$ of available phosphorus per $g$ (mean of 10 replicate analyses), which increased with the proportion of manure in the potting mix to $130 \mu \mathrm{g} \mathrm{g}^{-1}$ in potting mix amended with $15 \%$ (vol/vol) chicken manure. Phytotoxicity symptoms identical to those described above were observed within 2 weeks of planting.

\section{DISCUSSION}

Chicken manure compost gave better control of $P$. cinnamomi root rot on L. albus than cow, horse, or sheep manure. Low incidences of seedling death in chicken manure compost-amended potting mixes correlated with low populations of P. cinnamomi, high levels of microbial activity, and in particular the activity of endospore-forming bacteria.

On its own, organic matter content is a necessary, but not a sufficient, condition for suppressiveness $(3,7,13)$. Although all manure treatments significantly increased soil organic matter levels, not all manures suppressed pathogen populations or seedling symptoms. Organic matter provided by manure is high quality because of its cellulosic content and level of available energy and supports the growth of suppressive microbes (7). Weste and Vithanage (25) found that the most severe symptoms and most rapid spread of dieback caused by $P$. cinnamomi in
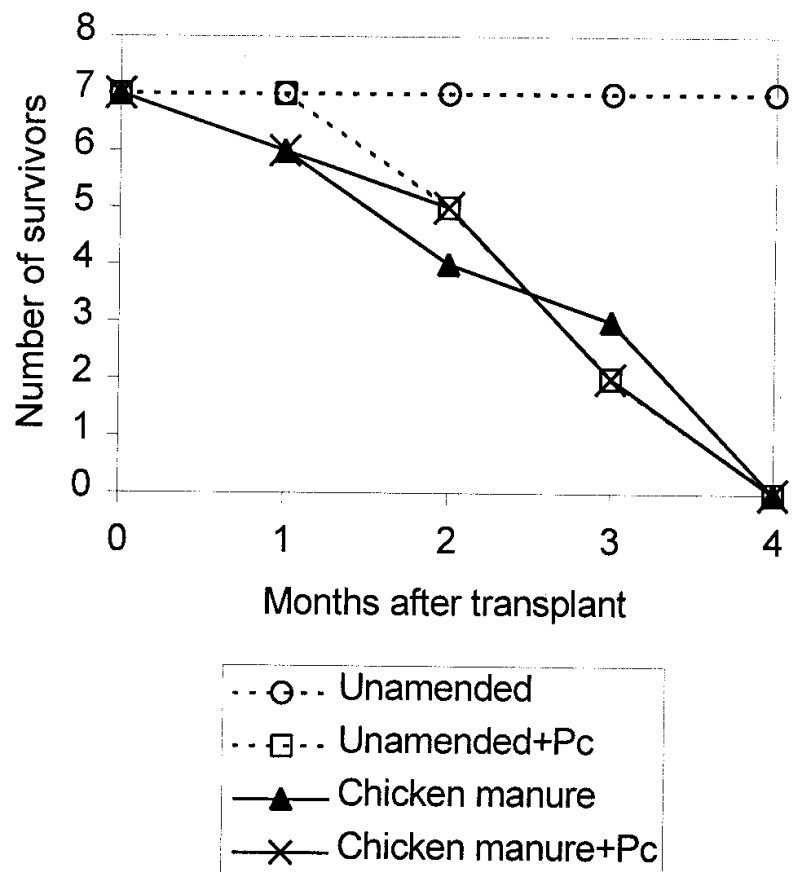

Fig. 6. Survival of Banksia spinulosa seedlings transplanted into unpasteurized sand-peat potting mix, following amendment with chicken manure and inoculation with Phytophthora cinnamomi $(\mathrm{Pc})$. The number of survivors indicates how many of the original seven seedlings in each treatment were alive at each observation. Significantly fewer $(P \leq 0.05)$ plants survived on amended and $P$. cinnamomi-infested potting mixes than on unamended, uninfested potting mix 2, 3 and 4 months after transplanting. There were no significant differences in the survival rates on amended or infested potting mixes.
Australian forests occurred on soils with low microbial activities and especially on soils with low populations of actinomycetes. Malajczuk and McComb (13) also noted that rhizosphere microflora, including bacteria and actinomycetes, were significantly higher on suppressive loam soils compared with those on disease-conducive lateritic soils in Western Australia. Our findings indicate that the survival of $L$. albus seedlings in $P$. cinnamomi-infested potting mix is positively correlated with the level of microbial activity and with populations of endosporeforming bacteria but negatively correlated with organic matter content and populations of actinomycetes. In our study, all manure treatments increased actinomycete populations, although this was not related to the ability of manures to suppress disease symptoms. These differences confirm the complex nature of disease suppression, the dynamic qualities of composts of different maturities, and the importance of understanding different environmental conditions (7).

The maturity of chicken manure affected its behavior. Chicken manure composts of all ages stimulate sustained levels of total biological activity exceeding $3.2 \mu \mathrm{g}$ of FDA hydrolyzed/minute/g of dry soil, the level predicted by Chen et al. $(4,5)$ and Hoitink et al. $(7,8,9)$ to endow general suppressiveness. However, we also found that the highest levels of total biological activity, in chicken manure composted for 2 weeks, coincided with the highest populations of $P$. cinnamomi, while biological activity and pathogen populations were lowest in fresh chicken manure. Fresh chicken manure is the hottest animal manure, being high in soluble nitrogen, phosphorus, and potassium (3). Three different forms of nitrogen (ammonium, nitrite, and nitrate) inhibit $P$. cinnamomi, both in soils and in vitro $(2,26)$. Tsao and Oster $(23)$ found that ammonia $(\mathrm{pH} 8.0)$ inhibited $P$. cinnamomi in vitro. High levels of ammonia in fresh chicken manure are directly toxic to $P$. cinnamomi; however, leaching and volatilization of ammonia during composting enables the growth of fast-growing saprophytes as well as pathogens that utilize readily available sugars. By 5 weeks, coinciding with the second phase of composting described by Hoitink and Boehm (7), thermophilic cellulose degraders and slower growing suppressive microbes begin to dominate the compost, and pathogen populations decline. This succession demonstrates the multifaceted and changing nature of actively composting manures.
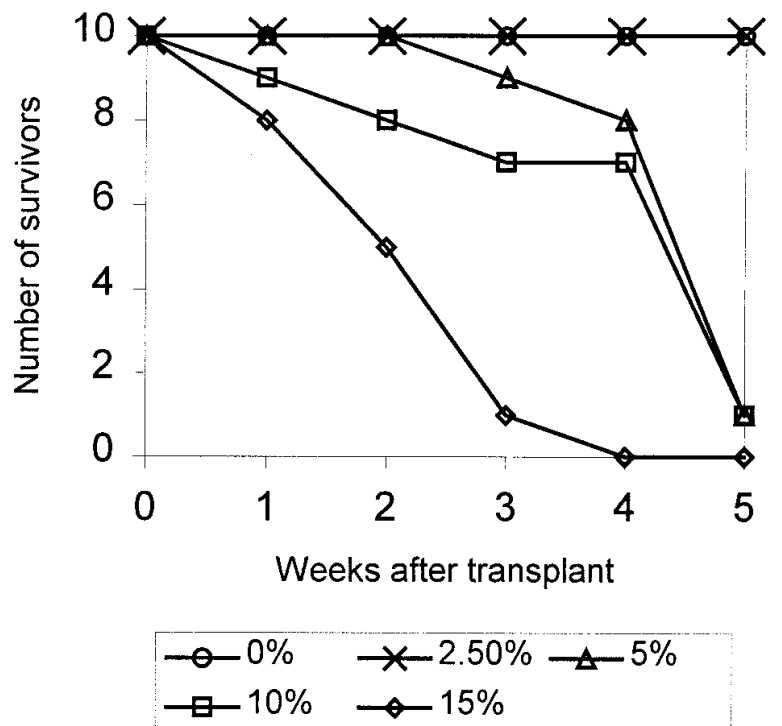

Fig. 7. Survival of Banksia spinulosa seedlings on pasteurized river sand amended with varying proportions $(0,2.5,5.0,10$, or $15 \%, \mathrm{vol} / \mathrm{vol})$ of chicken manure. Survival rates on $15 \%$ (vol/vol) chicken manure compost were significantly lower $(P \leq 0.05)$ than on unamended potting mix one or more weeks after transplant, or after 5 weeks on 5 or $10 \%$ amendment. 
The suppressive effects of compost result from interacting chemical, biological, and physical factors $(7,9)$. We attempted to distinguish the chemical and biological components of disease suppression by comparing the effects of chicken manure on pasteurized and nonpasteurized potting mix. In all cases, unpasteurized compost was more suppressive than pasteurized potting mix, suggesting that antagonism by endogenous soil microbes is a more significant factor than changes in soil chemistry and nutrient levels. This is supported by the good correlation we observed between compost amendment, endospore-forming bacterial populations, pathogen mortality, and low disease incidence.

The populations of other microorganisms (fluorescent pseudomonads and fungi) increased following manure amendments, but were not directly correlated with seedling survival and $P$. cinnamomi population. These organisms may exert an indirect effect on pathogen survival and should not be considered unimportant. Some isolates of fungi and fluorescent pseudomonads very strongly inhibit the growth of $P$. cinnamomi, both on plates and in pot trials $(22,24)$. Casale et al. (3) found that increased $P$. fluorescens populations following mulching were associated with increased avocado root weight and healthiness. These results highlight the potential to stimulate the growth of endogenous suppressive microbes through the use of organic soil amendments and indicate that it is not just total biological activity, but the types of microbes that make up the total, that are most important in biological control.

Commercial chicken manure caused severe phytotoxicity in $B$. spinulosa at levels as low as $5 \%$ ( $\mathrm{vol} / \mathrm{vol})$. Unlike the mild chlorosis induced in $T$. calycina, chicken manure is lethal to $B$. spinulosa, confirming a previous report (11) that attributed deaths to toxic levels of phosphorus in soils amended with chicken manure compost. The commercial chicken manure used for the $T$. calycina and $B$. spinulosa trials was at least 3 months older than that used in the L. albus trial. However, it strongly suppressed $P$. cinnamomi and caused phytotoxicity in B. spinulosa. Although we observed remarkably uniform effects with chicken manure from different batches, and of different ages, variation between batches of manure can hinder the adoption of biocontrol practices using organic amendments. Variation and the risk of failure or phytotoxicity can be reduced by the adoption of standardized production methods for manures (20).

Like Huber and Watson (10), we conclude that there are four benefits of applying organic amendments: (i) increasing the biological buffering capacity of the soil; (ii) reducing pathogen numbers during anaerobic composting; (iii) affecting nitrification and the form of nitrogen; and (iv) denying the pathogen a host. We are currently investigating the application of these results to the management of dieback caused by $P$. cinnamomi on naturally infected field sites. We are also examining whether lower rates of chicken or cow manures, in combination with other management strategies, can protect phosphorus-sensitive plants against dieback without causing phytotoxicity.

\section{ACKNOWLEDGMENTS}

This work was supported by The Australian Flora Foundation and Maud Gibson Trust. I. Aryantha thanks AUSAID for the award of a postgraduate scholarship. We also thank T. Mitakakis for her technical assistance through the project, M. Bailey for his advice on statistics, and $\mathrm{G}$. Weste for her valued contribution.

\section{LITERATURE CITED}

1. Bray, R. H., and Kurtz, L. T. 1945. Determination of total, organic and available phosphorus in soils. Soil Sci. 59:39-45.

2. Broadbent, P., and Baker, K. F. 1974. Behaviour of Phytophthora cinnamomi in soils suppressive and conducive to root rot. Austr. J. Agric. Res. 25:121-137.

3. Casale, W. L., Minassian, V., Menge, J. A., Lovatt, C. J., Pond, E., Johnson, E., and Guillemet, F. 1995. Urban and agricultural wastes for use as mulches on avocado and citrus and for delivery of microbial biocontrol agents. J. of Hortic. Sci. 70:315-332.

4. Chen, W., Hoitink, H. A. J., and Madden, L. V. 1988. Microbial activity and biomass in container media for predicting suppressiveness to damping-off caused by Pythium ultimum. Phytopathology 78:1447-1550.

5. Chen, W., Hoitink, H. A. J., and Schmitthenner, A. F. 1987. Factors affecting suppression of Pythium damping-off in container media amended with composts. Phytopathology 77:755-760.

6. Greenberg, R. S., Daniels, S. R., Flanders, W. D., Eley, J. W., and Boring, J. R., III. 1996. Medical Epidemiology. 2nd ed. Prentice-Hall International, Englewood Cliffs, NJ.

7. Hoitink, H. A. J., and Boehm, M. J. 1999. Control within the context of soil microbial communities: A substrate-dependent phenomenon. Ann. Rev. of Phytopathol. 37:427-446.

8. Hoitink, H. A. J., Madden, L. V., and Boehm, M. J. 1996. Relationships among organic matter decomposition level, microbial species diversity, and soilborne disease severity. Pages 237-249 in: Principles and Practice of Managing Soilborne Plant Pathogens. R. Hall, ed. The American Phytopathological Society Press, St. Paul, MN.

9. Hoitink, H. A. J., VanDoren, D. M., Jr., and Schmitthenner, A. F. 1977. Suppression of Phytophthora cinnamomi in a composted hardwood bark potting medium, Phytopathology 67:562-565.

10. Huber, D. M., and Watson, R. D. 1970. Effect of organic amendment on soil-borne pathogens. Phytopathology 60:22-26.

11. Leake, S., 1996. How to manage phosphorus sensitive plants. Aust. Hort. 94(10):55-60.

12. Lingappa, Y., and Lockwood, J. I. 1962. Chitin media for selective isolation and culture of actinomycetes. Phytopathology 52:317-325.

13. Malajczuk, N., and McComb, A. J. 1979. The microflora of unsuberized roots of Eucalyptus calophylla $\mathrm{R}$. Br. and Eucalyptus marginata Donn ex Sm. seedlings grown in soil suppressive and conducive to Phytophthora cinnamomi Rands. I. Rhizosphere bacteria, actinomycetes and fungi. Aust. J. Bot. 27: 235-254.

14. Nelson, D. W., and Sommers, L. E. 1982, Total carbon, organic carbon, and organic matter. Pages 539-594 in: Method of Soil Analysis Part 2. A.L. Page, ed. American Society of Agronomy Inc., Madison, WI.

15. Ribeiro, O. K., and Linderman, R. G. 1991. Chemical and biological control of Phytophthora species in woody plants. Pages 399-410 in: Phytophthora. J. A. Lucas, R. C. Shattock, D. S. Shaw, and L. R. Cooke, eds. Cambridge University Press, Sydney.

16. Roy, S. C., and Newhook, F. J. 1970. The influence of cattle excreta on sporulation of Phytophthora cinnamomi Rands. N.Z. J. Agric. Res. 13:308-314.

17. Sands, D. C., and Rovira, A. D. 1970. Isolation of fluorescent pseudomonads with a selective medium. Appl. Microbiol. 20:513-514.

18. Schnurer, J., and Rosswall, T. 1982. Fluorescein diacetate hydrolysis as a measure of total microbial activity in soil and litter. Appl. Environ. Microbiol. 43:1256-1261.

19. Shew, H. D., and Benson, D. M. 1982. Qualitative and quantitative soil assays for Phytophthora cinnamomi. Phytopathology 72:1029-1032.

20. Standards Australia. 1997. Composts, soil conditioners and mulchesAustralian Standard 4454. Standards Australia, Homebush, N.S.W.

21. Stewart, H. T. L., Hopmans, D. W., Flinn, D. W., and Croatto, G. 1990. Harvesting effects on phosphorus availability in mixed eucalypt ecosystem in southern Australia. For. Ecol. Manage. 36:149-162.

22. Stirling, A.M., Hayward, A.C., and Pegg, K.G. 1992. Evaluation of the biological control potential of bacteria isolated from a soil suppressive to Phytophthora cinnamomi. Australasian Plant Pathol. 21(4):133-142.

23. Tsao, P. H., and Oster, J. J. 1981. Relation of ammonia and nitrous acid to suppression of Phytophthora in soils amended with nitrogenous organic substances. Phytopathology 71:53-59.

24. Turnbull, L. V., Ogle, H. J., Stirling, A. M., and Dart, P. J. 1992. Preliminary investigations into the influence of Pseudomonas cepacia on infection and survival of proteas in Phytophthora cinnamomi infected potting mix. Sci. Hortic. 52:257-263.

25. Weste, G., and Vithanage, K. 1977. Microbial populations of three forest soils: Seasonal variations and changes associated with $P$. cinnamomi. Austr. J. Bot. 25:377-383.

26. Zentmyer, G. A., and Bingham, F. T. 1956. The influence of nitrite on the development of Phytophthora root rot of avocado. Phytopathology 46:121-124. 